\title{
Response of vegetation to temperature and precipitation in Xinjiang during the period of 1998-2009
}

\author{
XiaoMing $\mathrm{CAO}^{1,2}, \mathrm{Xi} \mathrm{CHEN}^{1 *}$, AnMing BAO ${ }^{1}$, Quan WANG $^{3}$ \\ ${ }^{1}$ Key Laboratory of Oasis Ecology and Desert Environment, Xinjiang Institute of Ecology and Geography, CAS, Urumqi 830011, \\ China; \\ ${ }^{2}$ Graduate University of Chinese Academy of Sciences, Beijing 100039, China; \\ ${ }^{3}$ Faculty of Agriculture, Shizuoka University, Shizuoka 422-8529, Japan
}

\begin{abstract}
In this paper, 10-day spatio-temporal response of vegetation to the change of temperature and precipitation in spring, summer, autumn and whole year during the period of 1998-2009 was analyzed based on the data of SPOT VEGETATION-NDVI and 10-day average temperature or precipitation from 54 meteorological stations in Xinjiang. The results show that the response of 10-day NDVI to temperature was more significant than that to precipitation, and the maximal response of vegetation to temperature and precipitation lagged for two 10-day periods. Seasonally, the effect of temperature and precipitation on vegetation NDVI was most marked in autumn, then in spring, and it was not significant in summer. The response of vegetation to 10-day change of meteorological factors was positive with a long affecting duration in spring, and it had a relatively short affecting duration in autumn and summer. Spatially, the 10-day maximal response of NDVI to temperature in northern Xinjiang was higher than that in southern Xinjiang. The correlation between the 10-day NDVI in whole year and the temperature in the $0-8^{\text {th }} 10$-day period was significantly higher than that between the annual NDVI and the annual temperature at all meteorological stations; the interannual change of NDVI was accordant well with the change of annual precipitation. However, the effect of precipitation within a year on NDVI was not strong. The results indicated that interannual change of temperature was not the dominant factor affecting the change of vegetation NDVI in Xinjiang, but the decrease of annual precipitation was the main factor resulting in the fluctuation of vegetation coverage. Ten-day average temperature was an important factor to promote vegetation growth in Xinjiang within a year, but the effect of precipitation on vegetation growth within a year was not strong.
\end{abstract}

Keywords: NDVl; temperature; precipitation; correlation; scale

\section{Introduction}

Vegetation plays a very important role in carbon-waterenergy cycle of terrestrial ecosystems (Xiao and Moody, 2005), and it is an indicator in global change research (Sun et al., 1998). Climate change is one of the causes resulting in the change of land cover (Lambin and Strahler, 1994). As a sensitive parameter to characterize the vegetation coverage and growth, Normalized Difference Vegetation Index (NDVI) can be used to reflect the change of vegetation coverage to a certain extent (Chen et al., 2001), and it has been extensively used in the research of environmental sci- ence, ecology and agriculture (Li et al., 2005; Morawitz et al., 2006; Zhang, 2006; Wang et al., 2007; Jarlan, 2008). Recently, the study on the relationship between NDVI and climatic factors became a hot topic (Fu et al., 2007), and many scholars researched the response of vegetation NDVI to temperature and precipitation at global and regional scales (Nemani et al., 2003; Mao et al., 2007; Li et al., 2008a, b; Song and Ma, 2008). Temperature and precipitation in Xinjiang obviously increased with the warming of global climate factors on vegetation and the response of vegeta-

\footnotetext{
Received 2010-11-23; accepted 2011-01-20 doi: 10.3724/SP.J.1227.2011.00094

* Corresponding author: Xi CHEN (E-mail: chenxi@ms.xjb.ac.cn)
} 
tion to meteorological factors at different spatial and temporal scales in Xinjiang need to be researched urgently.

The response of vegetation to climate change was widely researched in arid areas in China (Zhang, 2003; Xu, 2007; Hua, 2008; Dai, 2011). Gao et al. (2000) found that the correlation between vegetation and monthly precipitation or temperature was low. However, Chen et al. (2001) suggested that temperature change was the dominant factor to affect the vegetation NDVI change in western Xinjiang, but the vegetation NDVI change was jointly driven by both temperature and precipitation in Tarim Basin in southern Xinjiang, eastern Tianshan Mountains, etc. The result is different from the research of Guo et al. (2008), in which the correlation coefficient between NDVI and temperature was much higher than that between NDVI and precipitation in most regions of Xinjiang, and the effect of temperature on vegetation growth in life circle was higher than that of precipitation in northwest China. For the temperate desert vegetation, Li (2000) considered that the NDVI change in Xinjiang was obviously affected by both temperature and precipitation. The research of Li et al. (2009) revealed that water and heat conditions played an important role in vegetation growth of Gurbantunggut Desert in Xinjiang at annual scale. However, most researches focused on the whole Xinjiang, and different responses of vegetation between southern Xinjiang and northern Xinjiang to climate change has not been researched. At temporal scale, the response of vegetation to a short-term climate change was ignored (such as a 10-day change) (Cui et al., 2009). The effects of a short-term change of temperature and precipitation on vegetation NDVI in Xinjiang are remarkable because Xinjiang is located at arid area with a high day-and-night temperature difference, limited precipitation and high evaporation.

The effects of 10-day changes of temperature and precipitation on vegetation growth in life circle were analyzed based on the correlation analysis, and the different responses of vegetation NDVI between southern Xinjiang and northern Xinjiang to 10-day changes of meteorological factors were researched. Barnes interpolation was used to interpolate the values of annual temperature and precipitation at 54 meteorological stations in Xinjiang using DEM (Digital
Elevation Model) data. The correlation coefficients between the annual NDVI and the annual temperature and precipitation were calculated. The response of vegetation NDVI to temperature and precipitation in Xinjiang in recent 12 years was analyzed, and the different response of vegetation NDVI to temperature and precipitation in Xinjiang was researched.

\section{Materials and methods}

\subsection{Data}

The data included the 10-day maximized SPOT VEGETATION-NDVI in Xinjiang from the $10^{\text {th }}$ 10-day period in 1998 to the $30^{\text {th }} 10$-day period in 2009, the average temperature and precipitation data of 54 meteorological stations in Xinjiang during the period of January, 1998 to December, 2009, and DEM data in Xinjiang.

The SPOT VEGETATION-NDVI data were from the Image Processing and Filing Center of VITO Institute, Belgium, which has been improved by applying atmospheric correction, cloud removal, and bi-directional reflectance distribution function (BRDF) correction (Morawitz et al., 2006). The 10-day NDVI was obatined by a revised Maximum Value Composites (MVC) method (Max $\left(\mathrm{NDVI}_{1}, \mathrm{NDVI}_{2}, \ldots\right.$, $\left.\mathrm{NDVI}_{\mathrm{i}}\right)$ ), and the spatial resolution was $1 \mathrm{~km} \times 1 \mathrm{~km}$.

The temperature and precipitation data were from China Meteorological Data Sharing Service System. The DEM data with a spatial resolution of $90 \mathrm{~m} \times$ $90 \mathrm{~m}$ were from the CGIAR Consortium for Spatial Information (CGIAR-CSI). The boundary data of the study area were based on the standard drawing of the national boundaries in Xinjiang published by the Xinjiang Bureau of Surveying and Mapping in 2006 and the data were obtained after vectored and projected processing.

\subsection{Data preprocessing}

The combine command of ArcGIS 9.2 was used to extract NDVI values from $3 \times 3$ pixels around 54 meteorological stations in Xinjiang, and 10-day average temperature and precipitation data were also used to compose temporal serial data of every 10-day NDVI, average temperature and precipitation at these meteorological stations during the period of 1998-2009.

The Max command of ArcGIS 9.2 was used to max- 
imize the NDVI values so as to obtain the maximized annual NDVI values. Because the highest vegetation coverage in Xinjiang occurs during the period of June to September, the unavailable data of the $1^{\text {st }}-9^{\text {th }}$ 10-day period in 1998 and the $31^{\text {st }}-36^{\text {th }}$ one in 2009 did not impact the maximized NDVI values in the same years, and the annual NDVI values hereafter were the maximums; the data of every 10-day average temperature and precipitation in all the years were averaged and added to derive the average annual temperature and precipitation data of 12 years at the 54 meteorological stations, and Barnes interpolation and DEM data were used to interpolate the temperature and precipitation data at all the meteorological stations. The distribution maps of average annual temperature and annual precipitation during the period of 1998 to 2009 in Xinjiang with a spatial resolution of $1 \mathrm{~km} \times 1$ $\mathrm{km}$ were charted, and the temporal serial data of NDVI, annual temperature and annual precipitation at the same period were obtained.

\subsection{Methods}

\subsubsection{Interpolation method}

By Barnes interpolation the meteorological data during the study period were interpolated using DEM data.

(1) Barnes interpolation

Barnes interpolation is an exponential weighting interpolation method, and it is used to interpolate the data with different density to the coordinates of regular grids. The method includes two steps, i.e. the evaluation of the initially-estimated values and the addition of the corrected values, and the Gaussian weighting function is used as the low-pass filter. Weightings of meteorological stations are reduced with increasing distance between grids. An interpolated weighting can be expressed as:

$$
w=\exp \left[-\frac{r^{2}}{f(d n)}\right]
$$

Where $r$ is the distance between a meteorological station and a grid, and it can be derived from the latitude and longitude of the station; $f(d n)$ is the filtering parameter, and its value is affected by spatial distribution of meteorological stations, and $f(d n)$ affects the smooth degree of interpolation extent (Barnes, 1964; Kocin, 1983; Liston and Elder, 2006; Hu et al., 2008).
(2) Interpolation of air temperature

Many scholars interpolated the values of air temperature considering the features of terrain in recent years (Burrough, 2000). Dodson and Marks (1997) summed up the interpolations mostly corresponding to the change of air temperature with terrain and the most frequently used methods to interpolate the values of temperature at mountainous meteorological stations. It was assumed that the atmospheric layer of the mesosphere was stable, and there was a linear decrease of air temperature with the increase of altitude when interpolating. The measured values of air temperature at all meteorological stations were corrected at a datum plane with the following equation:

$$
T_{0}=T_{\text {stn }}-\Gamma\left(z_{0}-z_{s t n}\right) \text {. }
$$

Where $T_{s t n}$ is measured air temperature $\left({ }^{\circ} \mathrm{C}\right) ; Z_{s t n}$ is the altitude of meteorological station $(\mathrm{m}) ; Z_{0}$ is the altitude of a datum plane (m), and it is 0 when sea level is regarded as the datum plane; $\Gamma$ is the attenuation ratio of air temperature (Kunkel, 1989) (Table 1). Barnes interpolation was used to interpolate the values of air temperature at all meteorological stations at the datum plane (the spatial resolution was $1 \mathrm{~km} \times 1 \mathrm{~km}$ ), and the interpolated air temperature values derived at the datum plane were corrected to the air temperature values at the actual altitudes with the following equation based on $\Gamma$ (or measured value) and DEM data:

$$
T=T_{0}-\Gamma\left(z-z_{0}\right) .
$$

Where $T$ is the air temperature $\left({ }^{\circ} \mathrm{C}\right)$ interpolated for the place with altitude $Z(\mathrm{~m})$.

Table 1 Air temperature lapse rate variations for every month of the year in the Northern Hemisphere, and precipitation elevation adjustment factors

\begin{tabular}{ccc}
\hline Month & $\Gamma$ & $x$ \\
\hline 1 & 4.4 & 0.35 \\
2 & 5.9 & 0.35 \\
3 & 7.1 & 0.35 \\
4 & 7.8 & 0.3 \\
5 & 8.1 & 0.25 \\
6 & 8.2 & 0.2 \\
7 & 8.1 & 0.2 \\
8 & 8.1 & 0.2 \\
9 & 7.7 & 0.2 \\
10 & 6.8 & 0.25 \\
11 & 5.5 & 0.3 \\
12 & 4.7 & 0.35 \\
\hline
\end{tabular}


(3) Interpolation of precipitation

Because the change of precipitation with altitude was nonlinear, Barnes interpolation was also used to interpolate the values of precipitation at all the meteorological stations (the spatial resolution was $1 \mathrm{~km} \times 1$ $\mathrm{km})$ so as to derive a reference datum plane. The following equation was used to calculate the data of precipitation in the study area:

$$
P=P_{0}\left[\frac{1+x\left(z-z_{0}\right)}{1+x\left(z-z_{0}\right)}\right]
$$

Where $P_{0}$ is the interpolated precipitation $(\mathrm{mm})$ at a meteorological station; $x$ is the regulation coefficient of the precipitation with an altitude (Wu et al., 2009) (Table 1$) ; Z_{0}$ is the altitude of the interpolated meteorological station; and $Z$ is the altitude.

\subsubsection{Correlation coefficient}

The following equation was used to calculate the correlation coefficients between NDVI and temperature and precipitation using the NDVI data during the period of 1998 to 2009 from 54 meteorological stations in Xinjiang.

$$
r_{x y}=\frac{\sum_{i=1}^{n}\left(x_{i}-\bar{x}\right)\left(y_{i}-\bar{y}\right)}{\sqrt{\sum_{i=1}^{n}\left(x_{i}-\bar{x}\right)^{2}} \sqrt{\sum_{i=1}^{n}\left(y_{i}-\bar{y}\right)^{2}}} .
$$

Where $r_{x y}$ is the correlation coefficients between $x$ and $y ; x$ is the NDVI, $y$ is the temperature or precipitation; $n$ is the number of the samples; $\bar{x}$ and $\bar{y}$ are the average values of $x$ and $y$, respectively.

The correlation coefficients between the 10-day vegetation NDVI values in spring (from the $7^{\text {th }}$ to $15^{\text {th }}$ 10-day period), summer (from the $16^{\text {th }}$ to $24^{\text {th }} 10$-day period), autumn (from the $25^{\text {th }}$ to $33^{\text {rd }} 10$-day period) or whole year and the temperature or precipitation in the $0-8^{\text {th }} 10$-day period were calculated during the period of 1998 to 2009. Because of a possible lagged response, the lagged periods of NDVI to temperature or precipitation were also calculated (Thornton et al., 1997; Yao et al., 2009). The response in winter was not included. Based on the calculated results above, the absolute maximal correlation coefficient and the corresponding 10-day period (lagged period) were selected from 9 correlation coefficients of temperature or precipitation, and the regional differences of the maximal correlation coefficients and the corresponding 10-day period at all the meteorological stations were analyzed using ArcGIS 9.2. The correlations between the NDVI and the temperature or precipitation at meteorological station level were calculated under AMTLAB, and the correlations between the annual NDVI and the annual temperature or precipitation were derived using ArcGIS 9.2.

\section{Results}

\subsection{Response of vegetation NDVI to 10-day changes of meteorological factors}

\subsubsection{Temporal response of vegetation NDVI to 10-day changes of meteorological factors}

The correlations between all the 10-day NDVI and the 10-day average temperature were positive, in which the correlation coefficient in the $2^{\text {nd }} 10$-day period was the highest (0.849), and it was decreased with the following 10-day periods (Fig. 1a). The correlations between all the 10-day NDVI and the 10-day precipitation were universally lower than that between the NDVI and the temperature in the same period (Fig. $1 b)$. The correlation coefficient in the $2^{\text {nd }} 10$-day period was the highest, but the value was only 0.438 . Overall, the maximal response of vegetation to the change of temperature and precipitation lagged behind two 10-day periods in Xinjiang.

The correlations between NDVI and meteorological factors were seasonally different. The correlation coefficients between the 10-day NDVI and 10-day temperature in the $1^{\text {st }}-3^{\text {rd }} 10$-day period in autumn were higher than that in spring, while this was opposite in the $4^{\text {th }}-8^{\text {th }} 10$-day period, and with the lowest in summer (Fig. 1a). The correlation coefficient between the 10-day NDVI and the 10-day precipitation in spring was the highest (Fig. 1b).

Viewing from the lagged period, the maximal response of NDVI to temperature and precipitation lagged behind a 10-day period in spring; in summer, that to temperature two 10-day periods, and that to precipitation a 10-day period; in autumn, two 10-day periods. The duration of temperature effect on vegetation NDVI was the longest (about seven 10-day periods) in spring, and it was about six 10-day periods in autumn and summer. The response of NDVI to meteorological factors was the most sensitive in spring, and the duration was long; in summer, the effect of meteorological factors' change on vegetation growth was not obvious. 

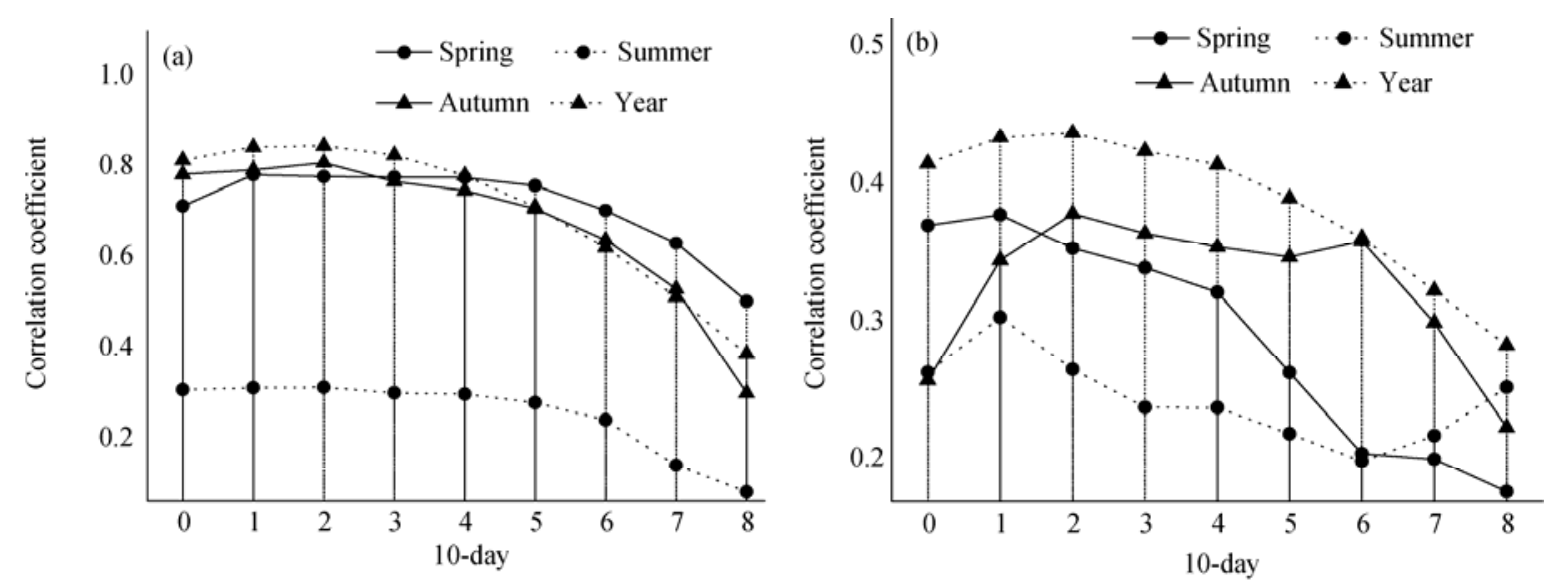

Fig. 1 Correlation coefficients between 10-day NDVI and temperature (a) or precipitation (b) (0,1...and 8 mean eight 10-day periods)

\subsubsection{Spatial response of vegetation NDVI to 10-day changes of meteorological factors}

There was a positive correlation between all the 10-day NDVI and the 10-day average temperature. The maximal response was more significant in northern Xinjiang than that in southern Xinjiang (Fig. 2a).

In spring and autumn, the maximal correlation coefficient between the 10-day NDVI and the 10-day average temperature in northern Xinjiang was higher than that in southern Xinjiang (Figs. $2 b$ and $2 d$ ). The distribution number of the meteorological stations selected for this study was the same, i.e. 27 meteorological stations in southern Xinjiang and 27 in northern Xinjiang. Quantitatively, the maximal correlation coefficients of 25 meteorological stations were higher than 0.85 in spring, among which 18 were distributed in northern Xinjiang and 7 in southern Xinjiang. The maximal correlation coefficients of 30 meteorological stations were higher than 0.85 in autumn, among which 19 were distributed in northern Xinjiang and 11 in southern Xinjiang.

On the contrary, the maximal response of NDVI to temperature in northern Xinjiang was lower than that in southern Xinjiang in summer. The maximal correlation coefficients of 22 meteorological stations were higher than 0.37, among which 6 meteorological stations were distributed in northern Xinjiang and 16 in southern Xinjiang (Fig. 2c).

Spatially, there was no significant difference of the maximal response of 10-day NDVI to 10-day precipitation between southern Xinjiang and northern Xinjiang, except for the Altay prefecture, for which the maximal correlation coefficient was the lowest (Fig. 3a).

In spring, the maximal response of NDVI to pre- cipitation was higher than that in summer and autumn. The maximal response in southern Xinjiang was universally higher than that in northern Xinjiang, and the maximal correlation coefficients of 26 meteorological stations were higher than 0.5 , among which 18 meteorological stations were distributed in southern Xinjiang and 8 in northern Xinjiang (Fig. 3b). These results revealed that precipitation in spring was an important factor to promote vegetation growth in southern Xinjiang.

In summer and autumn, most maximal correlation coefficients between the 10-day NDVI and the 10-day precipitation were positive, while there were the negative correlations in Altay prefecture and Tacheng city (Figs. 3c and 3d). These results implied that precipitation was not a dominant factor affecting vegetation growth in summer and autumn although precipitation in these seasons promoted vegetation growth to a certain extent.

\subsection{Response of vegetation NDVI to interannual changes of meteorological factors}

\subsubsection{Response of vegetation NDVI to interannual} changes of temperature

The correlation coefficient between the annual NDVI and the annual temperature was -0.090 , which implies that the vegetation coverage was slightly reduced with the increase of temperature in the areas of Barkol steppe, Bayanbuluk steppe, the oases in the Ili-Xinhe zone and the Hotan-Yutian-Qiemo zone, the piedmont desert steppes in the northern slope of Kunlun Mountains, etc. However, the NDVI was increased with the increase of temperature in the mountainous forest zone of Altay Mountains, the oases in the northern piedmont of Tianshan Mountains, some regions in 

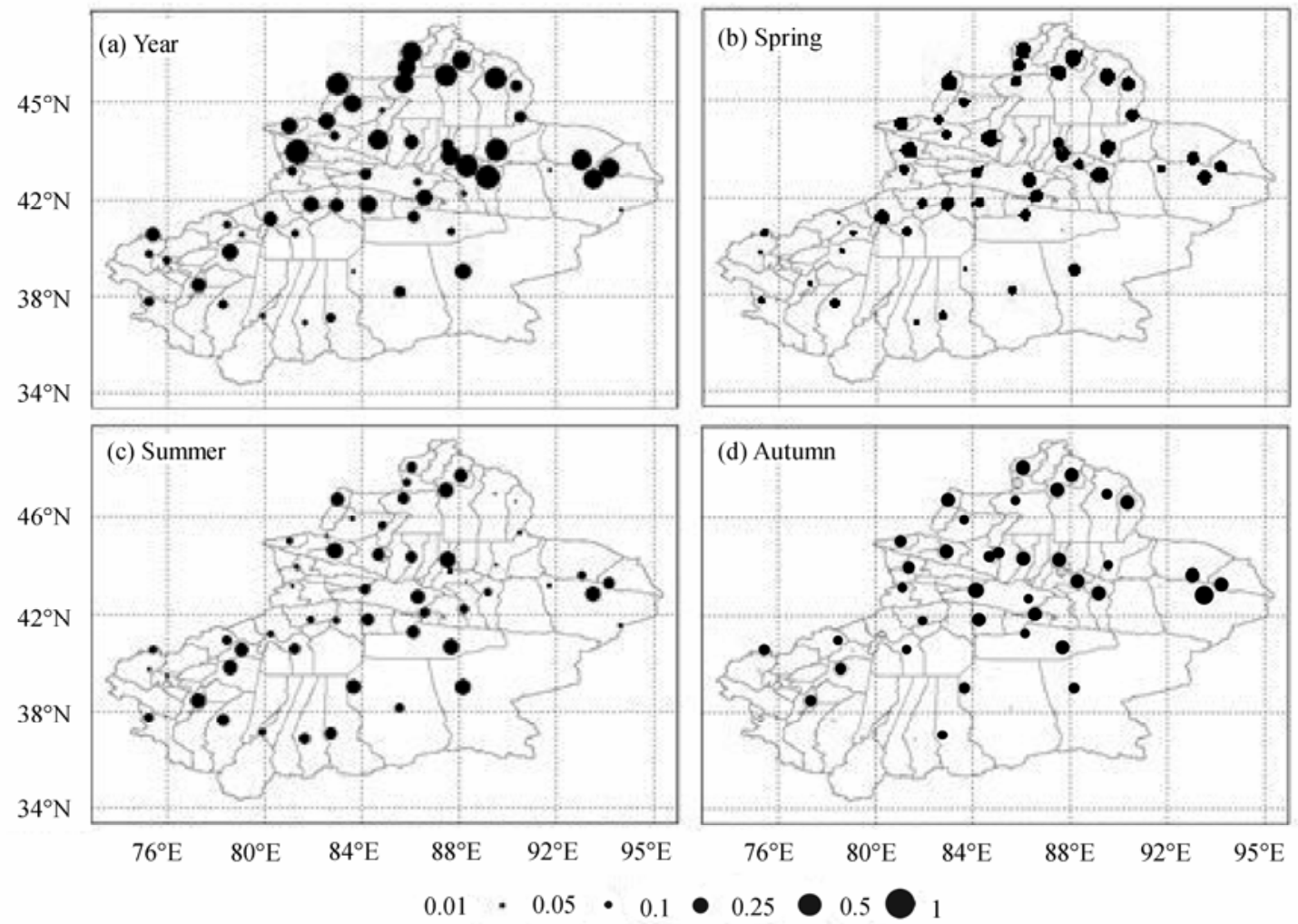

Fig. 2 Maximal correlation coefficients between 10-day NDVI and temperature $(0.01,0.05 \ldots .$. and 1 mean the correlation coefficient)
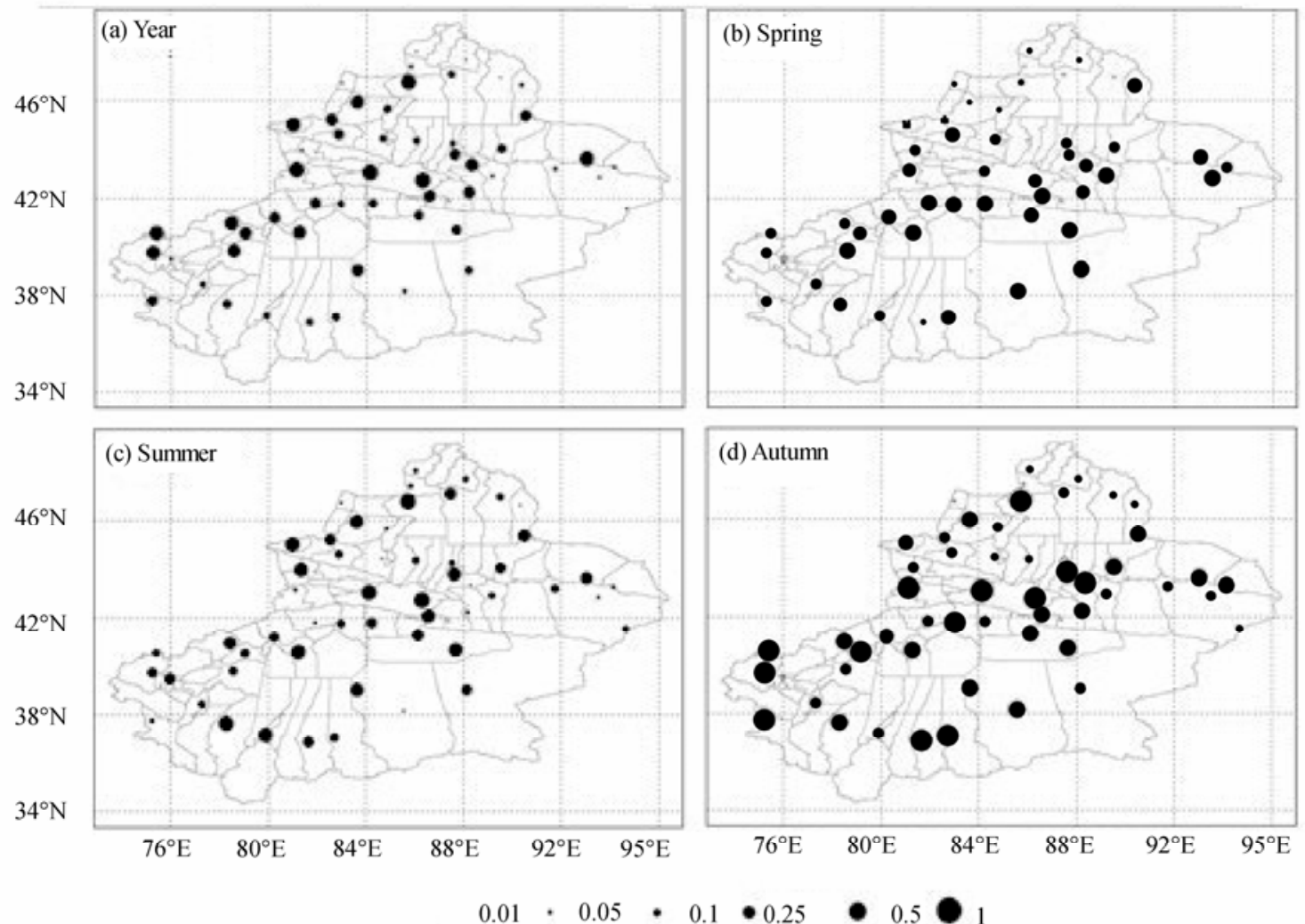

Fig. 3 Maximal correlation coefficients between 10-day NDVI and precipitation $(0.01,0.05 \ldots$. and 1 mean the correlation coefficient) 
Ili River Valley, the alpine deserts in Kunlun Mountains, etc (Fig. 4c).

\subsubsection{Response of vegetation NDVI to interannual changes of precipitation}

Annual precipitation in Xinjiang was accumulatively decreased by $7.48 \mathrm{~mm}$ during the period of $1998-$ 2009, and the decrease rate was $0.62 \mathrm{~mm} / \mathrm{a}$ (Fig. 4b). There was a weak positive correlation between the annual NDVI and the annual precipitation $(R=0.147)$, and a significant positive correlation between the annual NDVI and the annual precipitation in the mountainous forests in Altay Mountains, the oases in the northern slope of eastern Tianshan Mountains, the Ili River Valley and oases in the Shache-Pishan-Hotan-Yutian zone, while there was a negative correlation in the oases in the Usu-Shihezi zone in the northern slope of western Tianshan Mountains, Bayanbuluk steppe, the oases in the Aksu-Baicheng-Kuqa zone in the Tarim Basin and the piedmont desert steppe in the northern slope of Kunlun Mountains (Fig. 4d). The annual precipitation during the period of 1998-2001 was first reduced, and the vegetation NDVI in the same period was also significantly decreased. The an- nual precipitation was sharply increased and then decreased during the period of 2002-2009. However, the vegetation NDVI was obviously increased at first, and decreased during the period of 2003-2004, then increased again during the period of 2004-2009 (Fig. $4 b$ ). At annual scale, the interannual change of NDVI was consistent with the change of the annual precipitation, and the fluctuant decrease of annual precipitation was the dominant factor resulting in the fluctuation of vegetation coverage in Xinjiang.

\subsection{Response of vegetation NDVI to meteoro- logical factors at interannual and 10-day scales}

3.3.1 Response of vegetation NDVI to temperature at interannual and 10-day scales

The multi-year average 10-day NDVI and temperature in Xinjiang were normally distributed (Fig. 5a). The peak value of temperature occurred during the $19^{\text {th }}-20^{\text {th }} 10$-day period, and that of NDVI at the $21^{\text {st }}$ 10-day period which lagged behind about one 10-day period compared with that of temperature. The maximal correlation coefficients between the 10-day NDVI and the 10-day temperature in the $0-8^{\text {th }} 10$-day period were higher than 0.8 at most meteorological stations
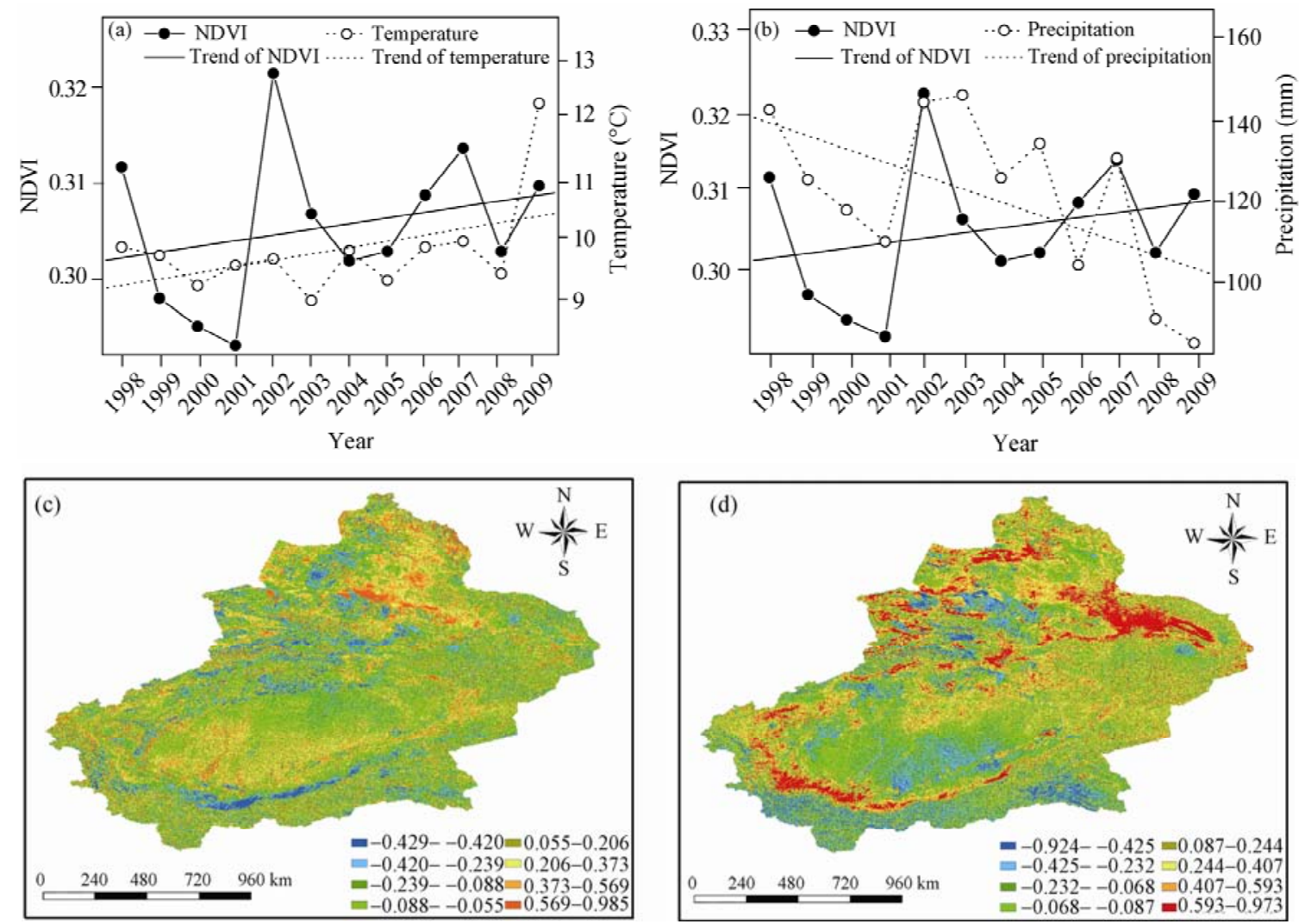

Fig. 4 The correlation between the annual NDVI and temperature $(a, c)$ or precipitation $(b, d)$ 
and than that between the annual NDVI and the annualtemperature (Fig. 5c). Moreover, the high correlation between the 10-day NDVI and the 10-day temperature did not imply the same correlation between the annual NDVI and the annual temperature. The results reveal that vegetation growth was closely related to temperature change within a year, especially the 10-day temperature change. That is, temperature was an important factor to promote vegetation growth within a year although the interannual change of temperature was not the dominant factor affecting the change of vegetation coverage in Xinjiang.

\subsubsection{Response of vegetation NDVI to precipitation at interannual and 10-day scales}

The peak value of precipitation occurred during the $19^{\text {th }}-20^{\text {th }} 10$-day period, and the response of NDVI to precipitation lagged behind one to two 10-day periods, and the peak value occurred in the $21^{\text {st }} 10$-day period (Fig. 5b). The correlation coefficient between the 10-day NDVI and the 10-day precipitation was 0.37 , which was significantly lower than that between the 10-day NDVI and the 10-day temperature. At meteorological level, the maximal correlation coefficient between the 10-day NDVI and precipitation in the
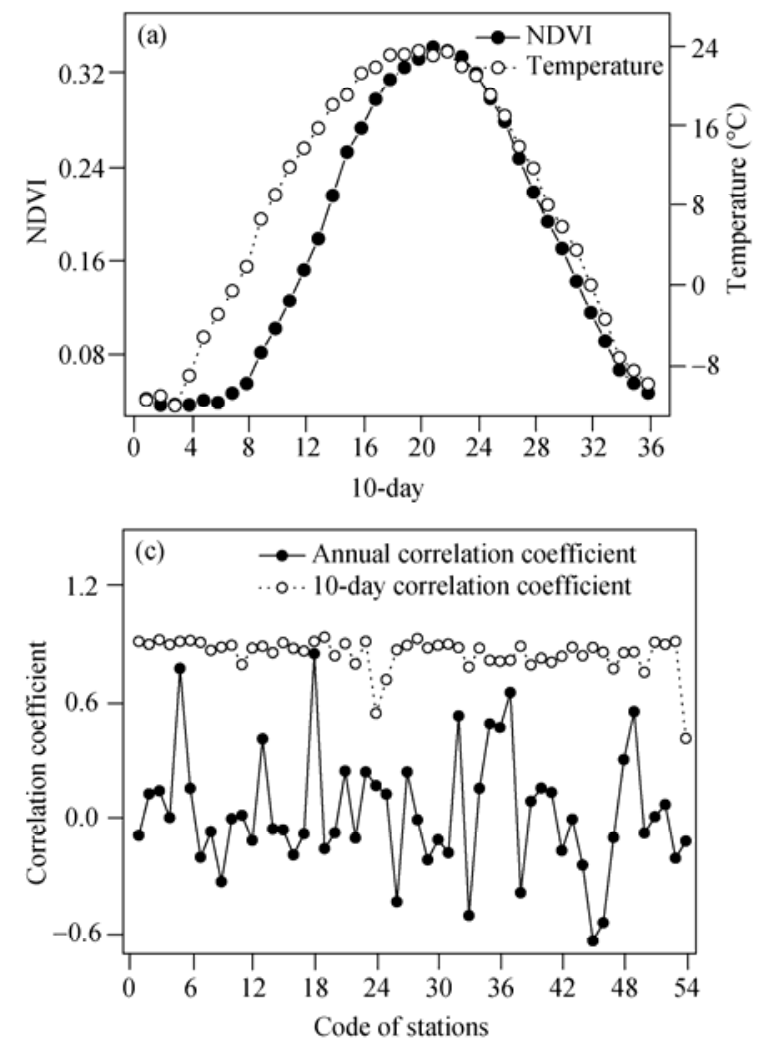

$0-8^{\text {th }} 10$-day period varied in the range of $0-0.55$, and the distribution of the correlation coefficients between the annual NDVI and the annual precipitation was dispersive (Fig. 5d). The results indicated that the increase of precipitation within a year could promote vegetation growth, but its effect was low; the fluctuation of the NDVI in recent 12 years was closely related to the annual precipitation, however, there was a negative correlation in some regions which was possibly caused by the thickness of dried soil layer under arid-hot climate during the study period, but the real driving mechanism needs to be specially researched based on fixed surface observation.

\section{Discussion}

During the process of global warming, the temperature in northern Xinjiang increased $1.4^{\circ} \mathrm{C}$ in recent 50 years, which was higher than the global average value in recent a century (Shi and Shen, 2002). Both annual vegetation NDVI and annual temperature were in a continuous increase trend in Xinjiang during the period of 1998-2009, and the temperature increase rate was $2.20^{\circ} \mathrm{C} / 12 \mathrm{a}$ (Fig. 4a). Chen (1999) found that the increase of temperature was contributed to the in crease
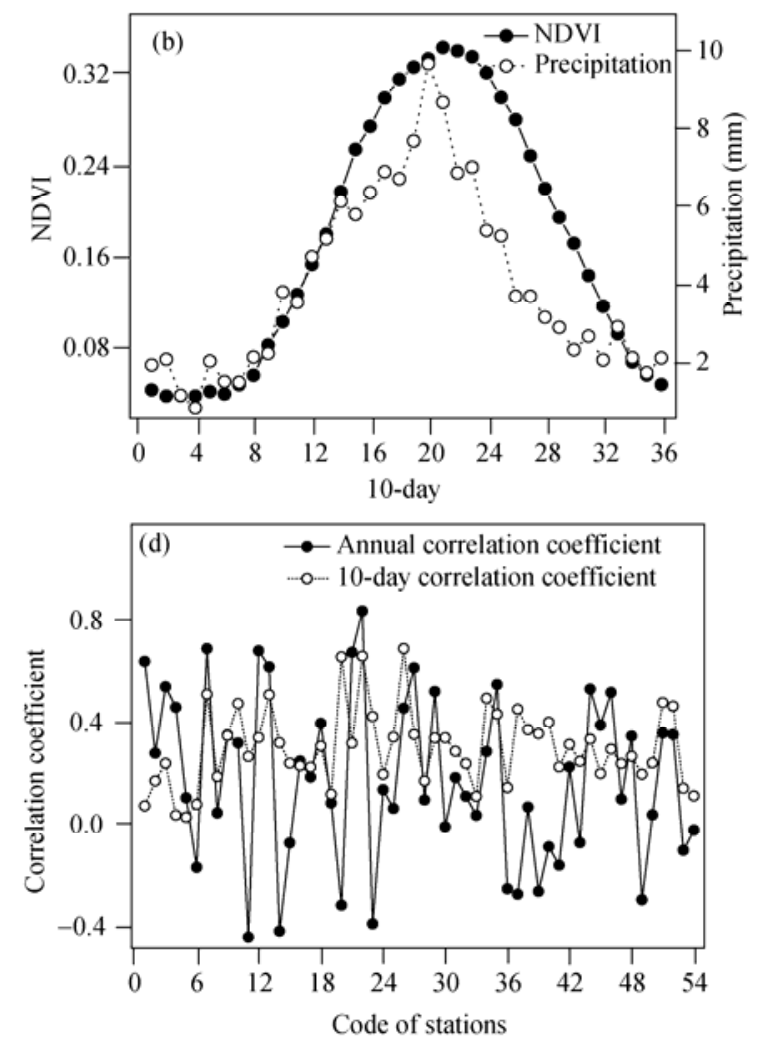

Fig. 5 Variation and correlation of NDVI, temperature $(a, c)$ or precipitation $(b, d)$ 
of NDVI in spring. However, it was not the dominant factor affecting vegetation growth, especially in the growth season (Yang, 2009), which is similar to the result of this study. Moreover, there is difference between the spatial structure of the correlation and the vegetation change, which reveals that the temperature change in recent 12 years is not a dominant factor affecting vegetation coverage change. The increase of temperature accelerated the surface evaporation, potentially intensified the shortage of water resources, and restricted the vegetation growth in Xinjiang where the precipitation is extremely low.

Precipitation was vital for spatial distribution of vegetation in arid and semiarid areas ( $\mathrm{Li}$ and Shi, 2000). The results showed that the 10-day change of precipitation could not affect the NDVI change within a year, which was contributed to the weakened correlation between farming vegetation NDVI and precipitation due to agricultural irrigation, and such effect was especially obvious in area with low precipitation (Weng et al., 2000). Yang (2009) considered that NDVI has stronger correlation with crop yield than that with precipitation. Crop yield in extremely arid area depends more on irrigation and water conservancy projects (Xia, 2008) than that on climate. Thus, further studies should be focused on how to quantify the effect of human activities on the decreasing correlation between precipitation and NDVI in Xinjiang within a year.

\section{References}

Barnes S. 1964. A technique for maximizing details in numerical weather map analysis. Journal of Applied Meteorology, 3(4): 396-409.

Burrough P, McDonnell P. 2000. Principles of Geographical Information Systems. Oxford University Press, 333.

Chen S Y, Guo J Y, Guo Z X, et al. 2009. Discipline of temporal and spatial variation of annual mean air temperature in arid and semiarid region in northwest China in the recent 46 years. Arid Land Geography, 32(3): 364-372.

Chen X Q, Yu R. 2007. Spatial and temporal variations of the vegetation growing season in warm-temperate Eastern China during 1982 to 1999. Acta Geographica Sinica, 62(1): 41-48.

Chen Y H, Li X B, Chen J, et al. 2001. Variation in NDVI driven by climate factors across China, 1983-1992. Acta Phytoecologica Sinica, 25(6): 716-720.

Chen Y Y, Chen N. 2009. Spatial-temporal variation of autumn rainfall in the last 50 years in Ningxia and its backgrounds on the large scale circulation. Arid Land Geography, 32(1): 9-16.

Cui L L, Shi J, Yang Y, et al. 2009. Ten-day response of vegetation NDVI to the variations of temperature and precipitation in Eastern China. Acta Geographica Sinica, 64(7): 850-860.

Dai S P, Zhang B, Wang H J, et al. 2010. Vegetation cover change and the driving factors over northwest China. Journal of Arid Land, 3(1):

\section{Conclusions}

Temporally, the response of the 10-day NDVI to the 10-day temperature was more significant than that to the 10-day precipitation, and the maximal response of vegetation to both temperature and precipitation lagged behind about two 10-day periods. Spatially, the maximal response of the 10-day NDVI to temperature in northern Xinjiang was totally higher than that in southern Xinjiang. There was no significant difference of the maximal response of the 10-day NDVI to the 10-day precipitation.

The correlation coefficient between the interannual change of NDVI and the interannual change of temperature was lower than that between all the 10-day NDVI values and temperature. The interannual change of NDVI was accordant well with the change of annual precipitation, whereas the correlations between all the 10-day NDVI values and precipitation in the $0-8^{\text {th }} 10$-day period were lower than that between the annual NDVI and the annual precipitation. The interannual change of temperature was the dominant factor affecting the change of vegetation NDVI in Xinjiang, but the fluctuant decrease of annual precipitation was the main factor resulting in the fluctuation of vegetation coverage in Xinjiang.

\section{Acknowledgements}

This work was supported by National Natural Science Foundation of China (40730633) and the Knowledge Innovation Program of the Chinese Academy of Sciences (KZCX2-YW-334).

25-33.

Dodson R, Marks D. 1997. Daily air temperature interpolated at high spatial resolution over a large mountainous region. Climate Research, 8: 1-20.

Fu X F, Yang S T, Liu C M, et al. 2007. Changes of NDVI and their relations with principal climatic factors in the Yarlungzangbo River Basin. Geographical Research, 26(1): 60-66.

Gao Z Q, Liu J Y. 2000. The study on driving factors and models of NDVI change based on remote sensing and GIS in China. Climatic and Environmental Research, 5(2): 155-164.

Guo N. 2008. The relationship between NDVI and climate elements for 22 years in different vegetation areas of Northwest China. Journal of Plant Ecology, 32(2): 319-327.

Hu J L, Zhang R H, Niu T, et al. 2008. A daily precipitation grid dataset with 0.1 resolution in Changjiang River valley and its precision. Journal of Natural Resources, 23(1): 136-149.

Hua W, Fan G Z. 2008. Preliminary analysis on the relationships between Tibetan Plateau NDVI change and its surface heat source and precipitation of China, Science in China, Series D: Earth Sciences, 51(5): 677-685.

Jarlan L, Mangiarotti S, Mougin E, et al. 2008. Assimilation of SPOT/VEGETATION NDVI data into a Sahelian vegetation dy- 
namics model. Remote Sensing of Environment, 112(4): 1381-1394.

Kocin P. 1983. An interactive Barnes objective map analysis scheme for use with satellite and conventional data. Journal of Climate and Applied Meteorology, 22(9): 1487-1503.

Kunkel K. 1989. Simple procedures for extrapolation of humidity variables in the mountainous western United States. Journal of Climate, 2(7): 656-670.

Lambin E, Strahler A. 1994. Indicators of land-cover change for change-vector analysis in multi-temporal space at coarse spatial scales. International Journal of Remote Sensing, 15(10): 2099-2119.

Li D L, Wei L. 2003. The present facts and the future tendency of the climate change in northwest China. Journal of Glaciology and Geocryology, 25(2): 135-142.

Li X B, Shi P J. 2000. Sensitivity analysis of variation in INDVI, temperature and precipitation in typical vegetation types across China. Acta Phytoecologica Sinica, 24(3): 379-382.

Li X H, Shi Q D, Chang S L, et al. 2008. Change of NDVI based on NOAA image in northwest arid area of China in 1981-2000. Arid Land Geography, 31(6): 940-945.

Li Y, Liu Y, Zhang P, et al. 2009. Research on the spatio-temporal change of NDVI in the Gurbantunggut Desert. Arid Zone Research, 26(5): 686-693.

Li Y C, Chen J, Gong P, et al. 2005. Study on land cover change detection method based on NDVI time series datasets: change detection indexes design. Journal of Basic Science and Engineering, 13(3): 261-275.

Li Z C, Wei Z G, Lv S H, et al. 2008. Variation characteristics of oasis vegetation in central Hexi in the late $20^{\text {th }}$ Century. Arid Land Geography, 31(1): 82-87.

Liston G, Elder K. 2006. A meteorological distribution system for high-resolution terrestrial modeling (MicroMet). Journal of Hydrometeorology, 7(2): 217-234.

Liu X D, Niu Y, Jing W M, et al. 2009. Comparison of principal meteorology factors inside \& outside forest in Qilian Mountains. Arid Land Geography, 32(1): 32-36.

Mahmood R, Li S L, Babar K. 2010. Caused of recurring drought patterns in Xinjiang, China. Journal of Arid Land, 2(4): 279-285.

Mao F, Lu Z G. 2007. Relations between AVHRR NDVI and climate factors in Northern Tibet in recent 20 years. Acta Ecological Sinica, 27(8): 3198-3205.

Morawitz D. 2006. Using NDVI to assess vegetative land cover change in central Puget Sound. Environmental Monitoring and Assessment, 114(1): 85-106.

Nemani R. 2003. Climate-driven increases in global terrestrial net primary production from 1982 to 1999. Science, 300(5625): 1560-1569.

Shi Y F, Shen Y P. 2002. Preliminary study on signal, impact and foreground of climatic shift form warm-dry to warm-humid in Northwest China. Journal of Glaciology and Geocryology, 24(3): 219-226.

Song Y, Ma M G. 2008. Variation of AVHRR NDVI and its relationship with climate in Chinese arid and cold regions. Journal of Remote Sensing, 12(3): 499-505.

Sun H Y, Wang C Y, Niu Z, et al. 1998. Analysis of the vegetation cover change and the relationship between NDVI and environmental factors by using NOAA time series data. Journal of Remote Sensing, 2(3): 204-210.

Thornton P, Running S, White M, et al. 1997. Generating surfaces of daily meteorological variables over large regions of complex terrain. Journal of Hydrology, 190(34): 214-251.

Wang J, Rich P, Price K. 2003. Temporal responses of NDVI to precipitation and temperature in the central Great Plains, USA. International Journal of Remote Sensing, 24(11): 1-4.

Wang L W, Niu Z, Ya X, et al. 2007. Land cover type classification and potential desertification area detecting in Xinjiang based on MODIS NDVI imagery. Arid Land Geography, 30(4): 573-578.

Wang Y J, Gao S Y, Ma Y Z, et al. 2010. Reconstructing the annual precipitation variation since 1989 based on tree-ring with in the western Hedong sandy land of Ningxia. Journal of Arid Land, 2(4): 286-294.

Weng G, Fu C B. 2000. Large scale features of the seasonal phenological responses to the monsoon climate in east China: multi-year average results. Chinese Journal of Atmosphere Sciences, 24(5): 676-682.

Wu J X, Zhang X M, Deng C Z, et al. 2010. Characteristics and dynamics analysis of Populus euphratica populations in the middle reaches of Tarim River. Journal of Arid Land, 2(4): 250-256.

Wu Y F, Wang X F. 2009. NDVI changes under the spatial patterns driven by climate factors in China. Arid Land Geography, 32(2): $166-174$

Xia J, Chen X, Zuo Q T. 2008. The scientific investigation of riverway renovations and ecological rehabilitation of the Tarim River and reconsideration. Journal of Natural Resources, 23(5): 746-753.

Xiao J, Moody A. 2005. A comparison of methods for estimating fractional green vegetation cover within a desert-to-upland transition zone in central New Mexico, USA. Remote Sensing of Environment, 98(3): 237-250.

Xu X K, Chen H, Zhang F, et al. 2007. Temporal and spatial change of vegetation cover in the northwest of China and factors analysis influencing on vegetation variation. Environmental Science, 28(1): 43- 47.

Yang G H, Bao A M. 2009. Study of the vegetation cover change and its driving factors over Xinjiang during 1998-2007. Jorunal of Glaciology and Geocryology, 31(3): 436-445.

Yao Y B, Xiao G J, Wang R Y, et al. 2009. Climatic changes of semi-arid region over the northwest China in recent 50a. Arid Land Geography, 32(2): 159-165.

Zhang J, Pan X L, Gao Z Q, et al. 2006. Estimation of net primary productivity of the oasis-desert ecosystems in arid west China based on RS-based ecological process. Arid Land Geography, 29(2): 255-261.

Zhang K C, Kai K J, Qu J J, et al. 2010. Dynamic changes of a typical linear dune in the Tenggar Desert. Journal of Arid Land, 2(4): 272-278.

Zhang Y D, Xu Y T, Gu F X, et al. 2003. Correlation analysis of NDVI with climate and hydrological factors in oasis and desert. Acta Phytoecologica Sinica, 27(6): 816-821.

Zhao C Y, Yan Y Y, Yimamu Y, et al. 2010. Effects of soil moisture on cotton root length density and yield under drip irrigation with plastic mulch in Aksu oasis farmland. Journal of Arid Land, 2(4): 243-249. 